\title{
MUJER INDÍGENA, DESIGUALDAD SOCIAL Y QUEBRANTAMIENTO DE SUS DERECHOS
}

Michael David Vergel Barrera

Liceth Ximena Martínez Muñoz

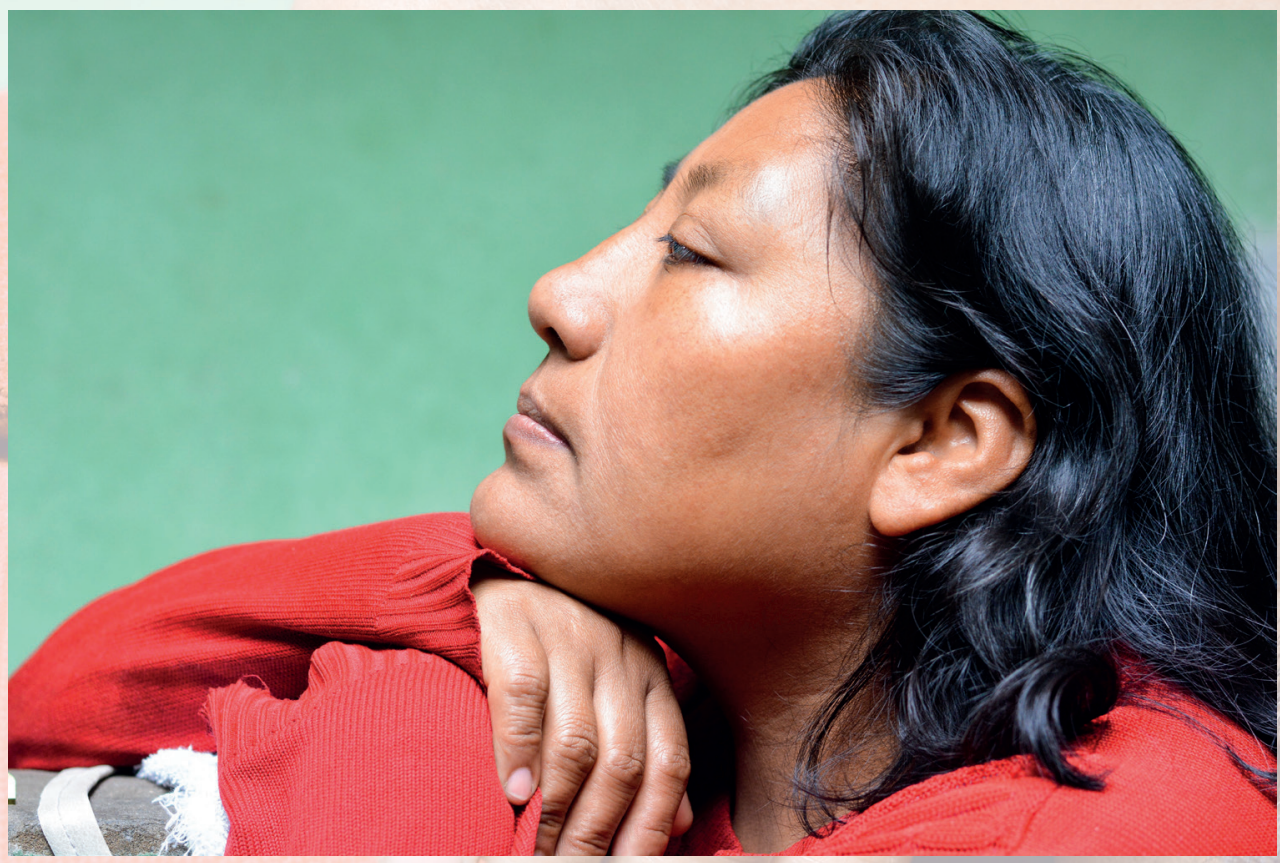





\title{
MUJER INDÍGENA, DESIGUALDAD SOCIAL Y QUEBRANTAMIENTO DE SUS DERECHOS
}

\author{
Michael David Vergel Barrera \\ Liceth Ximena Martínez Muñoz \\ Universidad Militar Nueva Granada
}

\section{Resumen}

La vulneración de derechos que sufre la mujer indígena como producto de situaciones cotidianas y de instituciones jurídicas que no le dan una atención necesaria viene de tiempo atrás; es incomprensible que las situaciones en que hoy se pueden encontrar las mujeres indígenas se asemejan a las que ocurrían hacía décadas y que la evolución para erradicar la violencia no haya obtenido mayor peso dentro de las comunidades indígenas. Así, debe brindarse mayor relevancia a estos temas, pues la mujer indígena ocupa un rol muy importante dentro de la sociedad, no solo en sus comunidades. Es evidente el clamor de equidad e igualdad en la participación política dentro y fuera de sus comunidades; se debe brindar valor a su opinión, tener acceso a derechos intrínsecos para un desarrollo social con garantías que le permitan trazar, con su autonomía, diferentes beneficios que les han sido negados durante generaciones.

Palabras clave: mujer indígena, vulneración de derechos, violencia, agresión, conflicto armado, tradición.

Los autores: Michael David Vergel Barrera, Estudiante de derecho de la Universidad Militar Nueva Granada, integrante del semillero de investigación Pensamiento jurídico crítico latinoamericano.

Liceth Ximena Martínez Muñoz, Estudiante de derecho de la Universidad Militar Nueva Granada, integrante del semillero de investigación Pensamiento jurídico crítico latinoamericano, diplomado en violencia contra la mujer del Politécnico Suramericano, curso en "El derecho de la mujer a una vida libre de violencias" de la Secretaría de la Mujer de Bogotá, actualmente activista del movimiento "Somos tejido" en procesos ambientales y sociales con enfoque de género en Sibaté, Cundinamarca.

Recibido: 15 de junio 2020; Evaluado: 3 de septiembre 2020; Aceptado: 1 de octubre 2020. 


\title{
INDIGENOUS WOMEN, SOCIAL INEQUALITY AND THE VIOLATION OF THEIR RIGHTS
}

\author{
Michael David Vergel Barrera \\ Liceth Ximena Martínez Muñoz \\ Universidad Militar Nueva Granada
}

\begin{abstract}
The rights violations indigenous women suffer as a result of daily situations and legal institutions that do not provide them necessary attention has been going on for some time. It is incomprehensible that the situations in which many indigenous women find themselves today are similar to those that occurred decades ago, and that efforts to eradicate violence have not had sufficient impact within indigenous communities. Thus, society must pay more attention to these issues, since indigenous women fulfill an important role in greater society, not only in their communities. The demand for equity and equality in political participation within and outside their communities is evident; their opinion must be valued, and they must have access to intrinsic rights for social development with guarantees that allow them to obtain, autonomously, different benefits that have been denied them for generations.
\end{abstract}

Keywords: indigenous women, rights violations, violence, aggression, armed conflict, tradition

Authors: Michael David Vergel Barrera, Law student at the New Granada Military University, member of the research group "Latin American critical legal thought."

Liceth Ximena Martínez Muñoz, Law student at the New Granada Military University, member of the research group "Latin American critical legal thought," graduate of a diploma course in violence against women from the South American Polytechnical, the Bogotá Secretary of Women course on "Women's right to a life free from violence," currently a member of the activist movement "Somos tejido" in environmental and social processes with a gender approach in Sibaté, Cundinamarca (Colombia).

Received: June 15, 2020; Reviewed: September 3, 2020; Accepted: October 1, 2020. 


\title{
MULHER INDÍGENA, DESIGUALDADE SOCIAL E QUEBRANTAMENTO DE SEUS DIREITOS
}

\author{
Michael David Vergel Barrera \\ Liceth Ximena Martínez Muñoz \\ Universidad Militar Nueva Granada
}

\section{Resumo}

A vulneração de direitos sofrida pela mulher indígena como produto de situações cotidianas e de instituições jurídicas que não lhe dão a atenção necessária acontece há muito tempo. É incompreensível que as situações em que as mulheres indígenas se encontram hoje em dia se assemelhem às que ocorriam há décadas e que a evolução para erradicar a violência não tenha tido maior peso dentro das comunidades indígenas. Assim, é preciso dar maior relevância a esses temas, pois a mulher indígena ocupa um papel muito importante dentro da sociedade, não apenas em suas comunidades. É evidente o clamor por equidade e igualdade na participação política dentro e fora de suas comunidades; deve-se valorizar a sua opinião e dar acesso a direitos intrínsecos para um desenvolvimento social com garantias que lhes permitam traçar, com sua autonomia, diferentes benefícios que lhes foram negados durante gerações.

Palavras-chave: mulher indígena, vulneração de direitos, violência, agressão, conflito armado, tradição.

Os autores: Michael David Vergel Barrera, Estudante de direito na Universidade Militar Nueva Granada, integrante do grupo de pesquisa "Pensamiento jurídico crítico latinoamericano".

Liceth Ximena Martínez Muñoz, Estudante de direito na Universidade Militar Nueva Granada, integrante do grupo de pesquisa "Pensamiento jurídico crítico latinoamericano", diplomado em violência contra a mulher do Politécnico Suramericano, curso em "O direito da mulher a uma vida livre de violências" da Secretaria da Mulher de Bogotá, atualmente ativista do movimento "Somos tejido" em processos ambientais e sociais com enfoque de gênero em Sibaté, Cundinamarca, Colômbia.

Recebido: 15 de junho 2020; avaliado: 3 de setembro 2020; aceito: 1 de outubro 2020. 


\section{Introducción}

La lucha por los derechos de las mujeres indígenas no es una sola, son varias luchas, resultado de la coligación de necesidades y precariedad que, tras la realización de diferentes tradiciones, se ven laceradas y dejan sin dignidad la postura femenina en la comunidad. La lucha comprende la necesidad de que los entes del Gobierno creen una política de garantía, en pro a su derecho a la vida, educación, salud, etc. Lideresas de las comunidades se han ido empapando del tema y buscando de manera profesional la dignificación de su género, que se ha visto tan afectado por políticas dentro de la comunidad indígena; así mismo, decretos estatales tienen una gran influencia en los comportamientos de la sociedad en general. Varias instituciones tienen en cuenta a la mujer indígena para que sea partícipe en decisiones que afecten a su cabildo, materializándose la inclusión de ellas en actividades donde la comunidad en general conozca esas problemáticas que quizá no ven debido a las tradiciones que estas tienen y tienden a normalizarse, sin saber la gran afectación que han estado cometiendo, pues la mujer indígena no debe ser vista con inferioridad.

Las mujeres indígenas son tejedoras de vida y las encargadas de transmitir el saber; por lo tanto, buscan preservar la vida de los suyos, porque de manera generacional se ha desvalorizado la vida, y se han acostumbrado a la ausencia de sus esposos, de sus padres y, muchas veces, de sus hijos. Por lo tanto, por medio de sus saberes buscan conservar la identidad étnica de sus tribus y que sus territorios sean respetados; con sus artesanías, tradición oral, tejidos, etc., procuran también contribuir con la economía de sus familias.

La presencia de violencia en las comunidades indígenas ha sido invisibilizada desde siempre, y con esto, podemos darnos cuenta de que el Gobierno colombiano no cuenta con políticas reales para enfrentar todos estos tipos de violencia que se reproducen con el tiempo. La mujer indígena requiere una política pública eficaz, fuerte y garantista, que le permita un desarrollo social, económico y cultural en pro a una vida digna.

La vulneración de derechos a la mujer indígena se puede visibilizar desde demasiadas perspectivas; su condición de mujer y de indígena ha sido la excusa, a través de los años, para ubicarla en situación de desigualdad para afrontar los riesgos a los que se ven sometidas como consecuencia del conflicto armado y por efecto del desplazamiento. La mujer indígena se ve obligada a afrontar situaciones nuevas, al cambiar su entorno, como se ha evidenciado durante años. Algunos testimonios 
recolectados por la Comisión Interamericana de Derechos Humanos (CIDH) son evidencia de ello:

Nos persiguen las imágenes de la angustia cuando tuvimos que salir corriendo con lo poco que teníamos o podíamos cargar para hacerle el quite a la muerte y desolación, en medio de esta angustia, quedamos a cargo de la familia aceptando actividades que no son tradicionales a nuestras culturas como emplearnos en el trabajo doméstico, o en el peor de los casos llegar a vender nuestros cuerpos. ${ }^{1}$

Los derechos de la mujer indígena no solo son vulnerados como consecuencia del conflicto armado, hay demasiadas aristas en las que se puede evidenciar esta situación, desde las propias comunidades y desde el Estado. Es preocupante observar, por medio de los estudios enfocados a las mujeres indígenas y en sí a la comunidad en general, cómo en gran parte del mundo es y ha sido muy común la poca protección y atención a las comunidades indígenas, pues, por ejemplo: "Tanto en Panamá como en Rusia, es aproximadamente seis veces más probable que las mujeres indígenas fallezcan durante el parto en comparación con la población no indígena”2.

La obligación que tiene el Estado de proteger y satisfacer los derechos de la mujer indígena en el ordenamiento colombiano según las disposiciones de este es una necesidad que ha sido plasmada durante años; es un claro ejemplo la protección que se les daba a las comunidades indígenas con la ley del Congreso expedida el 03 de marzo de $1822^{3}$, en la que se trata de hacer una recuperación de los derechos de los indígenas que habían sido oprimidos por el gobierno español; desde ese entonces, se infiere que la protección a las comunidades indígenas es necesaria para su subsistencia.

Trayendo este contexto a la actualidad, se podría decir que esa protección imperiosa que emana de las disposiciones legales colombianas para la protección de las comunidades indígenas está presente, y se manifiesta por medio de instituciones como la jurisdicción indígena, el fuero indígena que proviene de la anterior institución, el derecho de participación, entre otras. Si fuese así, sería palpable el

1 Comisión Interamericana de Derechos Humanos, "Las mujeres frente a la violencia y la discriminación derivadas del conflicto armado en Colombia", s. f., consultado febrero 18, 2020. http://www.cidh.org/ countryrep/colombiamujeres06sp/IV.htm\#_ftnref175

2 UNFPA, UNICEF, UN WOMEN, "Salud y mortalidad materna de las mujeres indígenas", s. f., consultado febrero 20, 2020. https://www.unfpa.org/sites/default/files/resource-pdf/factsheet_v20_Spanish.pdf

3 Federico Guzmán, "Capítulo 6. Indígenas y minorías étnicas", s. f., consultado mayo 3, 2020. http://www. unilibrebaq.edu.co/unilibrebaq/pdhulbq/html/capitulo6.html 
bienestar que estarían gozando las comunidades indígenas actualmente, pero la realidad es y ha sido otra ${ }^{4}$. El Estado colombiano ha reconocido los derechos de las comunidades indígenas, pero los mandatos que dicta no han sido cumplidos al día de hoy con la implementación de programas enfocados a la garantía de los derechos de los pueblos indígenas, según el Auto 092 de 2008. Después de doce años esos programas siguen sin ser ejecutados 5 .

Es importante conocer los derechos y puntos de vista de las comunidades indígenas, y las perspectivas de las mujeres indígenas, no hacerlo es una clara vulneración, tanto a sus derechos como a la identidad de la que deben gozar. Al quebrantarles sus derechos, también se estarían interrumpiendo las tradiciones y cosmovisiones que son inherentes a las comunidades indígenas, las cuales gozan de protección en la Constitución Política de Colombia ${ }^{6}$, en el apartado de principios fundamentales. A lo largo de la historia, dichos derechos se han intentado proteger mediante la óptica de la igualdad y por vía de tratados internacionales, como la Declaración de las Naciones Unidas sobre los derechos de los pueblos indígenas, que ayudan a que estas comunidades persistan con el pasar de los años ${ }^{7}$.

\section{Problema jurídico y método}

Es claro evidenciar la vulneración en cuanto a los derechos de las comunidades indígenas, pero, más allá de eso, se contempla que la situación de la mujer indígena es más compleja, puesto que se le vulneran sus derechos tanto por ser indígena como por ser mujer. Por ende, es necesario contextualizar de qué manera se vulneran los derechos de la mujer indígena, y evidenciar un estado del arte que permita comprender el fenómeno para abarcarlo. La metodología de la investigación fue cualitativa, y la principal herramienta fue la recolección de información y posterior sistematización, con el fin de establecer el estado del tema y un punto de partida para profundizarlo.

\footnotetext{
$4 \quad$ Ibíd.

5 Concejo de Bogotá, "En el marco del día de la Memoria y Solidaridad con las Víctimas del Conflicto Armado, la Concejala Ati Quigua propone a la Administración Distrital la creación de un Capítulo Étnico en el Plan de Desarrollo Distrital", abril 13, 2020, consultado mayo 3, 2020. http://concejodebogota.gov.co/en-elmarco-del-dia-de-la-memoria-y-solidaridad-con-las-victimas-del/cbogota/2020-04-13/080535.php

6 Luisa García, "La incorporación de la perspectiva de género y etnicidad en el campo jurídico colombiano", Justicia, vol. 21 , n. ${ }^{\circ} 30$ (2016): 74-76. http://revistas.unisimon.edu.co/index.php/justicia/article/view/756

7 Naciones Unidas, Resolución A/RES/61/295, Por la cual se aprueba la Declaración de las Naciones Unidas sobre los derechos de los pueblos indígenas (New York: ONU, 13 de diciembre de 2007).
} 


\section{Situaciones cotidianas}

Cuando se plantean situaciones cotidianas se deben visibilizar las condiciones en las que la mujer indígena debe sobrellevar su vida, decir dónde la ubicamos, el contexto derivado dentro de su comunidad en la que ha sido aislada y sometida, o bien sea afuera de esta, donde en Estado no provee soluciones garantistas ante dicha vulnerabilidad.

\section{Violencia intrafamiliar frente a violencia sexual}

Las creencias y la cosmovisión que tienen la mayoría de comunidades indígenas son innatas a las tradiciones de estas comunidades, pues pasan de generación en generación, y es lo que permite que dicha comunidad prevalezca. Pero, ¿es necesario que el rol que ha desempeñado la mujer indígena durante décadas siga siendo el mismo? Las raíces de la violencia provienen de los roles que han sido asignados al hombre y a la mujer, en los que el hombre siempre ha tenido la autoridad y se ha encargado del sustento del hogar, y la mujer, del cuidado de los niños y oficios domésticos. Ello generaba un desequilibrio hacia la mujer indígena, porque en la distribución del poder, la mujer siempre se encontraba en desventaja, al tener que asumir su rol sin ningún reproche, porque así lo determinaban las costumbres, sin importar que se vulneraran derechos inherentes a las mujeres.

Estas situaciones de violencia han sido impuestas a la mujer indígena por varios factores, como el conflicto que han sufrido las comunidades indígenas, y también por la cosmovisión de estas, en la cual la prevalencia del machismo es algo natural y se determina como un tipo de regla divina. Esta cosmovisión ha ido evolucionando, cambiando con el transcurso del tiempo, pues el hecho de ser mujer no la debe convertir en un sujeto en desventaja; ellas deben gozar de los mismos derechos y deberes. Con ello, se ha abierto más la perspectiva de la importancia y vital protección necesaria a la mujer indígena por medio de instituciones jurídicas ${ }^{8}$.

Frente a la violencia sexual, en la mayoría de los casos, los perpetradores son miembros de la misma comunidad, de la misma familia, personas cercanas; estas acciones son catalogadas como una práctica de dominación, en las que los niños

\footnotetext{
María Alejandra Ceballos Casas, Linda Lucía Narváez Zambrano, Marly Estephany Ortega Apraez, "Aproximaciones a la violencia doméstica en mujeres indígenas de Jambaló, Cauca, desde una mirada socioecológica" (tesis de maestría, Universidad Javeriana de Cali, 2019), 4-8. http://vitela.javerianacali.edu.co/bitstream/ handle/11522/11300/Aproximaciones_violencia_domestica.pdf?sequence=1\&isAllowed=y
} 
o niñas se convierten también en parte de esta historia, pues el hecho de que un niño o niña sea pequeño no significa que no entienda lo que está sucediendo. La violencia sexual deja consecuencias como las siguientes:

a. Miedo a la amenaza de sufrir violencia sexual directa en el futuro.

b. Duelos y afectaciones no resueltas, pues solo se presta atención a la víctima directa.

c. Necesidad de asumir tempranamente un rol de cuidado con la víctima directa, bien sea su madre o su hermana, sin tener las herramientas para hacerlo9.

Aunque la cita anterior haga referencia a una modalidad de violencia sexual en el conflicto armado, se puede tomar como análoga en el mismo caso de violencia, pues se evidencian acciones similares en el ambiente cotidiano de algunas comunidades indígenas ${ }^{10}$.

A pesar de que organizaciones buscan una mayor equidad dentro de las comunidades indígenas, se siguen presentando hechos de violencia intrafamiliar, abusos sexuales a niños y niñas menores de 14 años.

[...] Para las mujeres indígenas todavía hay desafíos enormes en materia de prevención y sanción a otros tipos de violencias de género, la más común es la violencia intrafamiliar. Dicen, además, que continúan viviendo en condiciones marcadas por la discriminación, el racismo, la exclusión, la extrema pobreza, el machismo y la falta de poder que se refleja en las inequidades que persisten. ${ }^{11}$

La autonomía de la que gozan las comunidades indígenas para mantener un control social dentro de la comunidad ha ido evolucionando con el pasar de los años; han sido más conscientes de las violaciones que sufren las mujeres y han implementado una pedagogía que les permite a las comunidades indígenas visibilizar que están

9 Centro Nacional de Memoria Histórica, "Memoria histórica con víctimas de violencia sexual: aproximación conceptual y metodológica” (Bogotá: CNMH, 2018), consultado noviembre 15, 2019. http://centrodememoriahistorica.gov.co/wp-content/uploads/2020/02/memoria-historica-con-victimas-de-violencia-sexual. pdf

10 Ibíd., 38-39.

11 Consejería Presidencial para los Derechos Humanos y Asuntos Internacionales, "Mujeres de los pueblos indígenas defienden sus derechos", s. f., consultado noviembre 19. 2019. http://www.derechoshumanos. gov.co/Prensa/2017/Paginas/mujeres-pueblos-indigenas-defienden-sus-derechos.aspx 
afrontando un problema que es serio y que debe ser foco de atención para todos, tanto así que se empieza a determinar el fortalecimiento de comités conciliadores y jurídicos de cada uno de los cabildos, con el fin de garantizar justicia, especialmente en los actos de violencia sexual. Además de estos comités conciliadores, también se encuentran redes de apoyo dentro de las mismas comunidades para que se detecte y se brinde atención a las víctimas; lo anterior ayuda a que dichos actos no queden impunes y también para que se empiece un proceso investigativo al agresor o agresora, que busca una rearmonización dentro de las comunidades, lo que facilita que estas tengan un bienestar por medio de la justicia ${ }^{12}$.

Las comunidades nasa y misak buscaron y determinaron entre las mujeres indígenas un símbolo que representara esa violencia como resultado interno de sus comunidades, y también de los conflictos que han sufrido y sufren, derivado del conflicto armado, siendo este símbolo plasmado en los chumbes (fajas de tela tejidas a mano de diferentes colores y figuras) como elementos que simbolizan las violencias sufridas y la cosmología de sus culturas. El centro de memoria histórica, por medio del resguardo Jámbalo, muestra cómo la comunidad intercambia opiniones desde la perspectiva de los más pequeños hasta los más grandes, y cataloga las opiniones al diferenciar solo los niños, de la perspectiva de hombres, mujeres y, aparte, de la comunidad. Lo anterior genera una pedagogía más eficiente en el campo del respeto que estaba siendo vulnerado hacia la mujer indígena, y que no había sido puesto en tema de conversación serio ante toda la comunidad, como un tema relevante por tratar que no debe quedar en el olvido, pues la construcción de la sociedad, de la comunidad, es tarea de todos los integrantes, con el fin de alcanzar su bienestar y armonía ${ }^{13}$.

La violencia a la que se ve sometida la mujer indígena tiene muchas repercusiones que afectan todo su ser, y esta proviene, por ejemplo, de malos tratos de su pareja o como consecuencia del conflicto armado. La Corte Interamericana de Derechos Humanos reconoce:

12 Colombia informa, "¿Cómo se maneja la violencia sexual en las comunidades indígenas del norte del Cauca?", s. f., consultado febrero 18, 2020. http://www.colombiainforma.info/como-se-maneja-la-violencia-sexual -en-las-comunidades-indigenas-del-norte-del-cauca/

13 Gestoras de Memoria Histórica del Resguardo de Jambaló, Hilando memorias para tejer resistencias: mujeres indigenas en lucha contra las violencias (Bogotá: Impresol Ediciones, 2015), 45-46. http://centrodememoriahistorica.gov.co/hilando-memorias-para-tejer-resistencias-mujeres-indigenas-en-lucha-contra-las-violencias/ 
[...] un acto de tortura puede ser perpetrado tanto mediante actos de violencia física como a través de actos que produzcan en la víctima un sufrimiento psíquico o moral agudo. Adicionalmente, este Tribunal ha reconocido que la violación sexual es una experiencia sumamente traumática que tiene severas consecuencias y causa gran daño físico y psicológico que deja a la víctima "humillada física y emocionalmente". De ello se desprende que es inherente a la violación sexual el sufrimiento severo. ${ }^{14}$

Los distintos tipos de violencia que afectan a la mujer indígena dentro del conflicto armado tienen grandes repercusiones dentro de las comunidades y sus tradiciones ancestrales, debido a los:

[...] diferentes usos y papeles que ha tenido la mujer dentro del conflicto, como si fuese un mero objeto, algo tan natural dentro del conflicto que hasta en ciertas regiones de Colombia se ha asimilado como algo que simplemente tiene que pasar, o se reprimen en su interior por el temor de ser masacradas, no sólo ellas y sus familias, sino sus pueblos enteros. Arrancando de raíz, su cultura, su tradición, su identidad y su nación. ${ }^{15}$

\section{Violencia doméstica y violencia física}

La violencia doméstica se puede determinar como el producto de una relación afectiva y de convivencia que ocasiona afectaciones para alguna de las partes que integra esa relación; causa lesiones físicas y psicológicas, y puede desembocar en embarazos no deseados, abortos, dificultades para sentir placer en las relaciones sexuales. En el ámbito psicológico, se puede representar mediante trastornos como depresión o ansiedad. Dichas lesiones desafortunadamente no se dan en solo una de esas modalidades, sino que la mayoría de veces, por no decir que en todas, se hacen efectivas ambas modalidades, y se debe prestar atención en ambas, pero fijando un poco más de interés en esa violencia física, pues la vulneración a los derechos humanos sobre las mujeres a través de la historia ha tenido un rango bastante alto. Estas circunstancias han generado en el ordenamiento colombiano

14 Corte Interamericana de Derechos Humanos, "Cuadernillo de jurisprudencia de la Corte Interamericana de Derechos Humanos, n. ${ }^{\circ}$ 4: Derechos humanos y mujeres", 2018, 41, consultado febrero 18, 2020. https:// www.corteidh.or.cr/sitios/libros/todos/docs/cuadernillo4.pdf

15 Luisa Fernanda García Lozano y Cristian Daniel Hernández Calderón, "Conflicto, derecho y mujeres en Colombia", s. f., consultado febrero 18, 2020. https://www.researchgate.net/profile/Cristian_Hernandez_Calderon/publication/315494653_CONFLICTO_DERECHO_Y_MUJERES_EN_COLOMBIA/ links/58d29cd0a6fdcc3ed382d589/CONFLICTO-DERECHO-Y-MUJERES-EN-COLOMBIA.pdf 
figuras como el feminicidio, una de las formas de visibilizar la violencia hacia la mujer por parte del hombre ${ }^{16}$.

La información concerniente a violencia doméstica en mujeres indígenas no tiene tantos registros en comparación con violencia doméstica de otras mujeres. Lo que lleva a esta situación es que la mujer indígena no denuncia, pues en la comunidad está mal visto. Como agravante de ello, se podría decir que existe un mayor número de estos abusos en contra de la mujer indígena en comparación con las mujeres no indígenas. El problema de la violencia de género desde hace pocos años está tomando fuerza dentro de las comunidades, lo que evidencia claramente la violencia doméstica. Como se dijo anteriormente, la importancia de la mujer indígena dentro de la comunidad es vital para el funcionamiento de esta, pues: "las mujeres indígenas son consideradas como líderes espirituales y son esenciales para la supervivencia de las mismas"17.

Las tasas de violencia doméstica no solo son evidentes en Colombia, sino que se presentan a escala mundial, como lo establece la Comisión Interamericana:

[...] que ha recibido información también sobre la prevalencia de la violencia doméstica contra mujeres indígenas de países tales como Bolivia, Brasil, Ecuador, Canadá, Estados Unidos, Guatemala, y México. Según la información recibida por la Defensoría de la Mujer Indígena de Guatemala (DEMI), se calcula que un tercio de las mujeres indígenas que viven con un hombre son víctimas de violencia intrafamiliar y las mujeres jóvenes presentan tasas de violencia más elevadas. $^{18}$

La violencia doméstica a la mujer indígena no es ajena a lo que sucede en la cultura occidental, pues las relaciones sentimentales en las que se ven inmersos los integrantes de las comunidades indígenas es similar a esta, donde los reclamos por parte de la mujer indígena a su pareja, y la respuesta de este, es una clara evidencia del machismo, al condicionar a la mujer indígena a situaciones de inferioridad, como se evidencia en el siguiente estudio de relato de una mujer indígena:

Ceballos, Narváez y Ortega, "Aproximaciones a la violencia doméstica...", 12-14.

17 CIDH, Las mujeres indígenas y sus derechos humanos en las Américas (Washington: OEA, 17 de abril, 2017), 80.

18 Ibíd., 82. 
Como vio que yo estaba dormida entonces salió y se había ido a hablar afuera, y siempre hacía lo mismo y a esa hora siempre llamaba a esa muchacha, entonces yo la última vez me hice la dormida y él salió, yo salí detrás de él y estaba escuchando la conversación y le hice el reclamo entonces de ahí era que él me pegaba (Mujer indígena 8). ${ }^{19}$

En esta contextualización, pareciese que las diferencias entre culturas hubieran desaparecido, pero al centrarse en la mujer indígena y el rol que ocupa en la comunidad, ha evolucionado en todos los aspectos. La cosmovisión de algunas comunidades no ata fielmente a los indígenas, en caso de que los roles que desempeñaban hombre y mujer indígena se distorsionaron y ya no son los mismos en algunos casos; la mujer en sí dentro de la cosmovisión debe tener más importancia, pues es la encargada de reproducir tradición y cultura, y ahora le recaen los oficios que debía desempeñar el esposo. Por este motivo, la mujer indígena comúnmente debe estar atenta al cuidado de la casa, de los hijos, de las tareas domésticas, de salir a trabajar y de cuidar de su esposo, pues es lo que le corresponde, cuidarlo. No se puede hacer una generalización de que si así actúa una relación indígena, todas actuarían del mismo modo, eso vulneraría el principio lógico de identidad y se incurriría en una falacia de generalización apresurada, pues en este caso de referencia también se encuentran mujeres indígenas que no actúan en su rol anterior de sumisión, sino que la mujer se complementa con su esposo, tanto en responsabilidades económicas como en necesidades domésticas; así, los roles y el papel dominante y sumiso no se evidencian, y más bien se busca un balance entre estos roles ${ }^{20}$.

El acceso a la justicia para la mujer indígena es muy precario. Este es el caso de una mujer indígena de Guatemala que había sido víctima de violencia de género y agresiones ejercidas por su marido: "Durante años me pegaba si participaba en reuniones con otras mujeres para hablar sobre nuestros derechos". "En una ocasión, estaba discutiendo con mi marido cuando de repente me arrojó una taza de café ardiendo. No me permitía salir a trabajar y me pegaba a menudo"21.

Esta mujer decidió demandar al agresor. En su relato, expresa cómo la relación con su marido cambió, sin embargo, relata que no abandonó a su marido por su falta

\footnotetext{
Ceballos, Narváez, Ortega, "Aproximaciones a la violencia...", 40.

Ibíd., 38-42.

21 Resumen Latinoamericano, "Mujeres e indígenas: cinco historias de discriminación en Guatemala", 2017, consultado febrero 4, 2020. http://www.resumenlatinoamericano.org/2017/01/22/ mujeres-e-indigenas-cinco-historias-de-discriminacion-en-guatemala/
} 
de sustento económico y por las recriminaciones que podría tener en un futuro por las propias mujeres de su comunidad, pues según sus tradiciones la mujer indígena tiene como deber el cuidado de su esposo y de sus hijos; la mujer indígena tiene un rol determinado, y no puede ejercer actividades como ir a la escuela o trabajar independientemente.

La importancia de los espacios de diálogo intercultural, según Uribe ${ }^{22}$, permite evidenciar que la definición de la identidad de mujer no se puede generalizar, pues la identidad caracteriza a cada una de las mujeres en especial; por ejemplo, la mujer indígena se caracteriza por su historia, cultura, luchas, por ende, el diálogo entre mujeres indígenas es importante para identificar problemáticas que solo pueden ser vistas desde el punto de vista de cada una de ellas. El debate en público sobre estas problemáticas es clave, pero debe tratarse con tacto, debido a que para ciertas mujeres puede tener una carga muy fuerte. Por ende, se deben aplicar diferentes temáticas pedagógicas, como ejercicios corporales, plenarias, lluvia de ideas, intercambio de prácticas culturales. Al establecer estos espacios se da a conocer el valor de la mujer indígena dentro de su comunidad y dentro de la sociedad en general, pues ella es la encargada de transmitir tradiciones.

\section{Instituciones jurídicas}

\section{Participación política}

La desigualdad que sufren las comunidades indígenas en general es el resultado de ese trato desigual que se les ha dado a través de los años; la mujer indígena en particular, por su condición de mujer y de indígena, tenía mayor dificultad en acceder a cargos dentro de su comunidad y en representación de esta. En el 2013, en Chile, varias dirigentes se reunieron en una asamblea de la Asociación Nacional de Mujeres Rurales e Indígenas (ANAMURI), y allí debatieron acerca del contexto de feminismo, que algunas integrantes consideraban que les era violentado; ellas reconocieron diferentes feminismos, y establecieron que en realidad buscaban la igualdad entre hombres, mujeres, ancianos, jóvenes, para llegar a una armonía como eje de su cosmovisión ${ }^{23}$.

Erika Uribe, "Un viaje ancestral. Mujeres afrocolombianas, indígenas y campesinas del Valle de Aburrá en diálogo de saberes intercultural", Revista Ratio Juris, vol. 13, n. ${ }^{\circ} 26$ (2018): 217-228.

23 Millaray Painemal Morales, "Mujeres indígenas, sus luchas de resistencia y la defensa de la vida", s. f., consultado mayo 12, 2020. https://wrm.org.uy/es/articulos-del-boletin-wrm/seccionl/mujeres-indigenas -sus-luchas-de-resistencia-y-la-defensa-de-la-vida/ 
El papel de una mujer indígena como representante de su comunidad hasta hace varios años era una novedad, como en el 2007, cuando "Ayutla se convirtió en el primer pueblo de la Sierra y de la Región Mixe en elegir, mediante su propio sistema normativo, a una mujer como presidenta municipal"24. El efecto que tuvo esta elección en esa comunidad fue darles a las mujeres indígenas participación, voz y voto que antes no habían sido considerados por el simple hecho de ser mujeres; es un ejemplo de la importancia que tienen las mujeres indígenas dentro de su comunidad. Hallarse como sujetos subalternos, atendiendo a esa subordinación generada por esa categoría que aún se puede ver implícita en las tradiciones de algunas comunidades, es lo que ha obstaculizado la voz de las mujeres indígenas.

En Colombia, por medio de la Asamblea Nacional de Mujeres Indígenas de la Organización Nacional Indígena de Colombia (ONIC), se fomenta la participación de las mujeres indígenas, quienes dan su opinión acerca de temas que son relevantes para su comunidad y para la mujer indígena en los diferentes escenarios en que se puedan encontrar; discuten y manifiestan problemáticas que han sido solucionadas por medio de providencias judiciales, pero que no han tenido aplicación, como el programa de protección de los derechos de las mujeres indígenas desplazadas. La falta de aplicación de normativas deja en una clara posición de desventaja a las comunidades indígenas; esa es la idea que quieren plasmar las mujeres indígenas al llevar a cabo estas concertaciones, por ello es fundamental que participen, su intervención es imprescindible a la hora de tomar y formular decisiones que afecten las comunidades indígenas a las que ellas también pertenecen ${ }^{25}$.

En el desarrollo de políticas públicas, paulatinamente se han agregado asuntos relacionados con la vulneración de derechos que sufre la mujer indígena; por tanto, la integración en cuanto a participación de la mujer indígena debe hacerse presente. Al ser un sujeto afectado, debe expresar sus propuestas e ideas para que se solucionen dichos asuntos. En Colombia se ha podido evidenciar que con esta participación se han realizado cambios estructurales importantes, como la ampliación de espacios en los que la mujer indígena se ve involucrada para debatir y fomentar

24 Yásnaya Elena A. Gil, "Mujeres indígenas, fiestay participación política", Dossier (noviembre, 2019), consultado mayo 12, 2020. https:/www.revistadelauniversidad.mx/articles/1157b614-c696-4872-9bl4-c48blc8680b5/ mujeres-indigenas-fiesta-y-participacion-politica

25 IX Asamblea Nacional de Mujeres Indígenas Autoridad Nacional de Gobierno Indígena de la ONIC, "Construyendo estrategias de participación para una incidencia efectiva", s. f., consultado mayo 14, 2020. https://www.onic.org.co/comunicados-onic/2502-ix-asamblea-nacional-de-mujeres-indigenas-dela-organizacion-nacional-indigena-de-colombia-onic-construyendo-estrategias-de-participacion-parauna-incidencia-efectiva 
sus propuestas con mayor protagonismo en las mesas de mujeres indígenas. Sin embargo, en un ámbito político de mayor jerarquía, como lo es la Cámara alta de la rama legislativa, hasta el momento no han sido ocupadas por ninguna mujer indígena, de ahí que en cuanto a la participación política, aún se encuentran en desventaja, como se demostró anteriormente ${ }^{26}$.

\section{Acceso a la educación}

El acceso a la educación de las comunidades indígenas se ha visto afectado por la precariedad y el olvido del Estado, ya que estas mismas comunidades siempre se han visto involucradas de manera involuntaria en los enfrentamientos armados de los grupos subversivos del país; así mismo, sus tierras han sido explotadas por terceros para producir coca, marihuana, etc. A estas comunidades, debido a su contexto social, cultural, económico, etc., se les dificulta la compra de uniformes, libros, cuadernos o herramientas tecnológicas, razón por la cual las familias desertan del proceso educativo de sus hijos. La desigualdad social se ha visto normalizada, romantizada, y se asume desde los medios que si estas personas no progresan es producto de la no perseverancia de las comunidades, la ausencia de templanza; de esa forma, se inicia la revictimización, culpar a aquel que es víctima del Estado, por la falta de inversión para dignificar las condiciones de estas comunidades para la ruptura de los círculos de pobreza en los que se han visto vinculadas de manera generacional.

Las cifras de la realidad que viven nuestras comunidades indígenas son alarmantes, ya que el "30,1 por ciento no registra ámbito educativo alguno"27, afirma un documento de Save The Children, en el 2016, que no ha sido renovado hasta hoy. Así, es posible denotar que la escolaridad no ha sido una necesidad suplida en un $100 \%$ para estos niños y niñas que nacen dentro de estas poblaciones indígenas, pese a que la educación es un derecho constitucional. De ello podemos concluir que se requiere una mayor inversión económica y social en esta población, una inversión real, que los recursos lleguen al origen de la necesidad, que se les dé prioridad y se les garanticen condiciones que hagan físicamente posible que los indígenas tengan acceso a la educación, y que esta no los obligue a renunciar a

26 Andrés Tabio Mahates y Jianna León Téllez, "El rol de la mujer indígena colombiana en el desarrollo de políticas públicas" (ponencia presentada en el Encuentro Nacional de Semilleros de Investigación de Facultades de Derecho, Bogotá D. C., septiembre 10-11, 2019).

27 El Tiempo, "Informe revela grave crisis de la educación en la población indígena", octubre 6, 2016, consultado mayo 5, 2020. https://www.eltiempo.com/vida/educacion/crisis-educativa-en-en-la-poblacion -indigena-en-colombia-34995 
sus raíces, a su idioma, a su gastronomía, etc. Los maestros que se dirijan a estas comunidades deben entender que se trata de comunidades especiales; el Estado, con su implementación educativa, no debe hacer que ellos se "adhieran" a otra realidad que no sea la suya, ya que dicho proceso ha sido gradual en estas poblaciones.

En un artículo del periódico El Tiempo, nos dicen: "El 86\% de los pueblos étnicos de Colombia no tiene acceso a una educación pertinente a su cultura, su contexto y su cosmovisión" ${ }^{\prime 2}$. Es decir, se burla el concepto de educación ante la precariedad y dicha adaptación de lo que consideramos "normal"; no se cumple con el principio de equidad de darle a cada quien lo que necesita, sino que se implementa la "igualdad" ante una educación que es excluyente, por las condiciones, el idioma, la cultura y el mismo contexto en general. Razón por la cual los niños evidentemente no son tratados con justicia social ante su especial protección.

La entidad encargada de la educación de los pueblos indígenas es la Organización de las Naciones Unidas para la Educación, la Ciencia y la Cultura (UNESCO), la cual es guiada por la "Política de compromiso con los pueblos indígenas"29. Su fuero radica en que estas comunidades deben tener el mismo acceso a la educación que aquellas personas que no pertenecen a estas mismas comunidades, razón por la que se les debe garantizar, priorizar, ante las condiciones de vulnerabilidad en las que se encuentran; asegurar que sí será posible una educación conforme con sus orígenes étnico-culturales, sin que se vuelva una acción de desenraizar a dichos niños del seno de su comunidad, sin obligarlos a la cristianización, sin remitirlos a la creencia de otros dioses que no sean los que se les han inculcado a través de la tradición oral de sus pueblos.

Es complicado para los habitantes de estas comunidades poder ir a una institución educativa, pero lo es más el hecho de mantenerse en ella, al ser menospreciados, tratados de manera discriminatoria por como hablan, como se visten y su mismo nombre; todo ello, sinónimo de burla. Por esto, los indígenas no están dispuestos a perder su cultura por una educación que no les garantiza sus derechos, que busca hacerlos parte de una sociedad que siempre los ha discriminado, al considerarlos "atrasados", maltratarlos como si fuesen seres inferiores, para intentar sustituir su identidad. Por esta razón, en el artículo 15 de la Declaración de los Derechos de los pueblos Indígenas de la ONU, se considera que: "Los pueblos indígenas

\footnotetext{
Ibíd.

29 MinEducación, "Atención educativa a grupos étnicos", s. f., consultado mayo 6, 2020. https://www.mineducacion.gov.co/1759/articles-235111_Atencion_educativa_a_Grupos_Etnicos.pdf
} 
tienen derecho a establecer y controlar sus sistemas e instituciones educativas proporcionando educación en sus propios idiomas, de manera que se respeten sus métodos culturales de enseñanza y aprendizaje." 30

Consecuentemente, es más fácil en estas comunidades dejar a las mujeres sin ni siquiera la oportunidad de pisar la escuela, porque han sido educadas dentro de las comunidades para suplir las necesidades del hogar, ya que el concepto "mujer", es decir, lo que nosotros consideramos adultez, a estas niñas se les atribuye desde el momento en que tienen su primera menstruación, entre los 11 y 14 años, edad en la que ya pueden tener relaciones sexuales y casarse. Antes de que estas mujeres sean casadas y formen un hogar, son obligadas a mantener el cuidado de sus hermanos menores; deben aprender a cocinar, tejer y ayudar con la economía del hogar, lo cual no ocurre con los hombres de las comunidades.

Entonces, ¿qué se requiere para una buena escolarización de las comunidades indígenas? Se requiere un enfoque diferencial, el cual:

1. Esté basado en las comunidades indígenas y se ajuste a sus calendarios, permitiendo a los niños formar parte de las ceremonias, cosechas y otras partes vitales de la vida en su comunidad.

2. Se lleve a cabo, en su mayor parte, en la lengua materna del niño, arraigada en el respeto a la comunidad y a sus mayores y en el conocimiento que el niño necesitará para ser un miembro competente de su comunidad.

3. Incluya a todas las generaciones en lugar de dividirlas: trabajando con los mayores, padres y abuelos.

La UNESCO ${ }^{31}$, en compañía del Ministerio de Educación de Colombia, ha planteado la etnoeducación, desde 1985, la cual consiste en educar a personas pertenecientes de las comunidades indígenas como maestros para que estos puedan enseñar de manera significativa en sus cabildos. En Colombia hay 710 cabildos reconocidos, con 68 lenguas indígenas; ello fortalecería la educación bilingüe, ya que desde la Constitución de 1991 se reconoce a estos pueblos y a su lengua nativa como aquella en la que deben ser educados, sin forzarlos a hablar y entender el castellano.

\footnotetext{
MinEducación, "Atención educativa a grupos étnicos".

31 UNESCO, "Política de colaboración de la UNESCO con los pueblos indígenas", s. f., consultado marzo 8, 2020. https://es.unesco.org/indigenous-peoples/policy
} 
A través de la gestión realizada por el Ministerio de Educación, se ejecutó una nueva visión para abordar la etnoeducación: "diálogos interculturales con grupos étnicos" 32 , la cual consistió en la conformación de la Comisión Pedagógica Nacional, encargada de la ejecución de políticas étnicas, acordes con las necesidades. Así mismo, a partir de los estudios culturales y sociológicos de la nación, se desarrolló la cátedra de Estudios Afrocolombianos, la cual se debía impartir en todas las instituciones educativas de nuestro país. Hoy por hoy, no se conoce un estudio que demuestre la efectividad de esta o que realmente haya sido implementada en colegios públicos y privados.

Lo anterior se ha dado, conforme el diálogo, por medio de la comisión de trabajo de los pueblos indígenas, con la que buscan obtener tres componentes y vincularlos de manera gradual al aprendizaje de estas comunidades indígenas ${ }^{33}$. Los componentes son: en primer lugar, el pedagógico, para que se mantenga la cosmovisión cultural sin la flagelación de sus creencias; en segundo lugar, la necesidad de implementar la participación política de estos pueblos, para que de esta manera y como ciudadanos tengan la oportunidad de elegir y ser elegidos; en una última instancia, el componente administrativo, con el fin de brindarles herramientas que les permitan un crecimiento económico; con esto se brindaría el crecimiento microempresarial para que las familias obtengan beneficios económicos y se reduzcan los círculos de pobreza.

El decreto que respalda la educación de los pueblos indígenas es el 1953 de 2013; allí se les reconoce la independencia en cuanto a la decisión de sus procesos de educación superior con enfoque diferencial. Así mismo, se busca que estos estudiantes de comunidades indígenas tengan acceso a las diferentes universidades del país, mediante un "Fondo llamado Álvaro Ulcique Chocue, que se realiza en compañía de ICETEX"34. Consecuentemente, en el 2018, se realizó el reconocimiento de la primera universidad indígena pública, con el fin de que se incremente la continuidad educativa y se disminuya la deserción de los estudiantes; con ello se generan mayores posibilidades de empleo y la creación de emprendimientos propios.

\footnotetext{
SURVIVAL, "Escolarización y pueblos indígenas", s. f., consultado marzo 8, 2020. https://www.survival. es/sobre/escolarizacion

33 UNESCO, "Política de colaboración de la UNESCO con los pueblos indígenas".

34 MinEducación, Atención educativa a grupos étnicos.
} 


\section{Acceso a la salud}

La poca atención recibida por parte de las comunidades indígenas las afecta gravemente; se ven perjudicados derechos tan esenciales como el derecho a la salud, a una vida digna, a la identidad cultural y muchos más. Hablando en concreto del derecho a la salud de una mujer indígena en un país como Colombia, departamentos como el Vaupés, con mayoría de población indígena, no cuenta con una buena cantidad de hospitales y centros de salud; estos son muy limitados en relación con el número de habitantes. Así, llegar a un centro de salud requiere más esfuerzo del que se tendría que hacer en una ciudad central como Bogotá, lo cual representa un obstáculo claro de acceso a este tipo de prestaciones, como se evidencia en la Sentencia T-357 del 26 de mayo de $2017^{35}$.

Los Estados tienen conocimiento de demasiadas falencias que existen sobre las comunidades indígenas, y que afectan en mayor medida a las mujeres indígenas, pero no se ha evidenciado un cambio tan progresivo que permita observar que las cosas han estado cambiando para bien. Esta información ha sido planteada por el Fondo de Población de las Naciones Unidas (UNFPA), el Fondo de las Naciones Unidas para la Infancia (UNICEF) y la ONU Mujeres (UN WOMEN) ${ }^{36}$, como resultado de un foro con información de países como Nicaragua, Costa Rica, Senegal y Kenia. Las condiciones de la mujer indígena de dichos países son análogas a las condiciones de las mujeres indígenas de Colombia; comparten situaciones que experimentan las mujeres indígenas, por ejemplo, cuando están embarazadas. Así:

- El hospital se encuentra muy lejos.

- El personal del hospital no habla el mismo idioma.

- El personal del hospital es maleducado/las considera inferiores.

- Quieren hacer las cosas a su manera, no a la de ellas.

- No preguntan ni escuchan lo que quieren.

El acceso a la salud en general para las comunidades indígenas es escaso, y ese impacto tiene más fuerza en las mujeres indígenas, pues ellas son las que se encuentran

\footnotetext{
35 Corte Constitucional, Sentencia T-357 de 26 de mayo de 2017, M. P. Gloria Stella Ortiz Delgado.

36 UNFPA, UNICEF, UN WOMEN, "Salud y mortalidad materna de las mujeres indígenas".
} 
en situación de embarazo. Deben recibir una prestación asistencial adecuada con sistemas de salud apropiados para su contexto indígena, que respete sus tradiciones y formas de pensar adecuados al entorno sociocultural en el que se encuentren ${ }^{37}$; sumado a la falta de estas condiciones, algunas mujeres indígenas evitan asistir a centros de salud, pues podrían poner en peligro su cónyuge, por el hecho de que la jurisdicción ordinaria en el caso colombiano considera que se es mujer después de los 18 años de edad, y acceder al sistema de salud teniendo menos de esta edad, siendo mujer y en estado de embarazo, ante la cultura occidental se estaría hablando de que el cónyuge de esta mujer indígena incurre en un tipo penal, y tal premisa en la mayoría de comunidades indígenas no es seguida del mismo modo por las tradiciones y cosmovisiones que las identifican, como se evidencia en la Sentencia T- 921 de $2013^{38}$.

Se evidencia que la esperanza de vida en la comparación de pueblos indígenas con pueblos que no lo son es alarmante; ello disminuye su calidad de vida, debiendo ser al contrario, teniendo una calidad de vida superior, pero no es así, puesto que no se da una relevancia significativa a las comunidades indígenas, ya que estas llevan consigo tradiciones que llevan años y aún se preservan, debiendo ser esta premisa imperante sobre las disposiciones que los Estados prevean sobre sus territorios, porque en realidad:

[...] [hay] poca salud, que se hace sentir con más intensidad entre las mujeres indígenas. Los pueblos indígenas experimentan desproporcionadamente altos niveles de mortalidad materna e infantil, desnutrición, enfermedades cardiovasculares, VIH/SIDA y otras enfermedades infecciosas. Las mujeres indígenas experimentan estos problemas de salud con especial intensidad, ya que se ven afectadas en forma desproporcionada por los desastres naturales y los conflictos armados. Además, a medida que aumenta el número de problemas de salud pública de otra índole, como el uso indebido de estupefacientes, el alcoholismo, la depresión y el suicidio, son necesarios esfuerzos urgentes y concertados para mejorar la situación de salud de los pueblos indígenas. ${ }^{39}$

United Nations, "Salud", s. f., consultado mayo 18, 2020. https://www.un.org/development/desa/ indigenous-peoples-es/areas-de-trabajo/salud.html

38 Corte Constitucional, Sentencia T-921 del 05 de diciembre de 2013, M. P. Jorge Ignacio Pretelt Chaljub.

39 United Nations, "Salud". 


\section{Conclusiones}

Las comunidades indígenas reconocidas desde el multiculturalismo de la Constitución de 1991 han sido, en presencia del Estado, víctimas de múltiples vulneraciones de derechos; lo cual es aún más grave si consideramos que son un sujeto de especial protección. Encontramos así que la mujer indígena es flagelada y olvidada por su condición de ser mujer y pertenecer a dichas comunidades; así, pese a que la norma es positiva y vigente, no se anexa a la realidad sociológica de estas mujeres. Vivimos en realidades paralelas, en las que el Gobierno no cumple con lo eternamente expuesto en el papel.

La inequidad se reproduce con fuerza y estas mujeres piden ser escuchadas, razón por la cual se necesita que se creen o se reformen instituciones con enfoque diferencial étnico y de género, para que estas tengan acceso a la justicia y se les garanticen sus derechos inherentes, como el derecho a la vida, la sexualidad, la educación, la salud, etc. Así, sería posible mejorar sus condiciones de vida y romper los círculos de violencia, pobreza, desigualdad, ausencia de oportunidades, etc. Consecuentemente, se requiere que les sean brindadas soluciones palpables a la comunidad femenina indígena de cada una de las 102 comunidades reconocidas del país, las cuales han sido desplazadas, tanto geográficamente de sus terrenos, como de su cultura y sus lenguas, y condenadas al olvido, como si su condición fuese una enfermedad de la que deben deshacerse para ser aceptados en el país.

\section{Referencias}

Ceballos Casas, María Alejandra, Linda Lucía Narváez Zambrano y Marly Estephany Ortega Apraez. "Aproximaciones a la violencia doméstica en mujeres indígenas de Jambaló, Cauca, desde una mirada socioecológica" (tesis de maestría, Universidad Javeriana de Cali, 2019). http://vitela.javerianacali.edu.co/bitstream/handle/11522/11300/ Aproximaciones_violencia_domestica.pdf?sequence $=1$ \&isAllowed $=y$

Centro Nacional de Memoria Histórica. "Memoria histórica con víctimas de violencia sexual: aproximación conceptual y metodológica". Bogotá: CNMH, 2018. http:// centrodememoriahistorica.gov.co/wp-content/uploads/2020/02/memoria-historicacon-victimas-de-violencia-sexual.pdf

CIDH. Las mujeres indigenas y sus derechos humanos en las Américas. Washington: OEA, 17 de abril, 2017.

Colombia informa. "¿Cómo se maneja la violencia sexual en las comunidades indígenas del norte del cauca?". S. f., consultado febrero 18, 2020. 
Comisión Interamericana de Derechos Humanos. "Las mujeres frente a la violencia y la discriminación derivadas del conflicto armado en Colombia”. S. f., consultado febrero 18, 2020. http://www.cidh.org/countryrep/colombiamujeres06sp/IV.Htm \#_ftnref175 Concejo de Bogotá. "En el marco del día de la Memoria y Solidaridad con las Víctimas del Conflicto Armado, la Concejala Ati Quigua propone a la Administración Distrital la creación de un Capítulo Étnico en el Plan de Desarrollo Distrital". S. f., consultado mayo 3, 2020. http://concejodebogota.gov.co/en-el-marco-del-dia-de-la-memoriay-solidaridad-con-las-victimas-del/cbogota/2020-04-13/080535.php

Consejería Presidencial para los Derechos Humanos y Asuntos Internacionales. "Mujeres de los pueblos indígenas defienden sus derechos". S. f., consultado noviembre 19, 2019. http://www.derechoshumanos.gov.co/Prensa/2017/Paginas/mujeres-pueblosindigenas-defienden-sus-derechos.aspx

Corte Constitucional. Sentencia T-357 de 26 de mayo de 2017. M. P. Gloria Stella Ortiz Delgado.

Corte Constitucional. Sentencia T-921 del 05 de diciembre de 2013. M. P. Jorge Ignacio Pretelt Chaljub.

Corte Interamericana de Derechos Humanos. "Cuadernillo de jurisprudencia de la Corte Interamericana de Derechos Humanos no 4: Derechos humanos y mujeres", 2018, consultado febrero 18, 2020. https://www.corteidh.or.cr/sitios/libros/todos/docs/ cuadernillo 4.pdf

El Tiempo. "Informe revela grave crisis de la educación en la población indígena". Octubre 6, 2016, consultado mayo 5, 2020. https://www.eltiempo.com/vida/educacion/ crisis-educativa-en-en-la-poblacion-indigena-en-colombia-34995

García Lozano, Luisa Fernanda y Hernández Calderón Cristian Daniel. "Conflicto, derecho y mujeres en Colombia”. S. f., consultado febrero 18, 2020. https://www.researchgate. net/profile/Cristian_Hernandez_Calderon/publication/315494653_CONFLICTO_ DERECHO_Y_MUJERES_EN_COLOMBIA/links/58d29cd0a6fdcc3ed382d589/ CONFLICTO-DERECHO-Y-MUJERES-EN-COLOMBIA.pdf

García, Luisa. "La incorporación de la perspectiva de género y etnicidad en el campo jurídico colombiano". Justicia, vol. 21, n. 30 (2016): 70-85. http://revistas.unisimon.edu. co/index.php/justicia/article/view/756

Gestoras de Memoria Histórica del Resguardo de Jambaló. "Hilando memorias para tejer resistencias: mujeres indígenas en lucha contra las violencias. Bogotá: Impresol Ediciones, 2015. http://centrodememoriahistorica.gov.co/hilando-memorias-paratejer-resistencias-mujeres-indigenas-en-lucha-contra-las-violencias/

Gil, Yásnaya Elena A. "Mujeres indígenas, fiesta y participación política". Dossier, consultado mayo 12, 2020. https://www.revistadelauniversidad.mx/articles/ 1157b614-c6964872-9b14-c48blc8680b5/mujeres-indigenas-fiesta-y-participacion-politica 
Guzmán, Federico. "Capítulo 6. Indígenas y minorías étnicas". S. f., consultado mayo 3, 2020. http://www.unilibrebaq.edu.co/unilibrebaq/pdhulbq/html/capitulo6.html IX Asamblea Nacional de Mujeres Indígenas Autoridad Nacional de Gobierno Indígena de la ONIC. "Construyendo estrategias de participación para una incidencia efectiva". S. f., consultado mayo 14, 2020. https://www.onic.org.co/comunicadosonic/2502-ix-asamblea-nacional-de-mujeres-indigenas-de-la-organizacion-nacionalindigena-de-colombia-onic-construyendo-estrategias-de-participacion-para-unaincidencia-efectiva

MinEducación. "Atención educativa a grupos étnicos". S. f., consultado mayo 6, 2020. https://www.mineducacion.gov.co/1759/articles-235111_Atencion_educativa_a_ Grupos_Etnicos.pdf

Naciones Unidas. Resolución A/RES/61/295, Por la cual se aprueba la Declaración de las Naciones Unidas sobre los derechos de los pueblos indígenas. New York: ONU, 13 de diciembre de 2007.

Painemal Morales, Millaray. "Mujeres indígenas, sus luchas de resistencia y la defensa de la vida". S. f., consultado mayo 12, 2020. https://wrm.org.uy/es/articulos-del-boletin-wrm/ seccion 1/mujeres-indigenas-sus-luchas-de-resistencia-y-la-defensa-de-la-vida/

Resumen Latinoamericano. "Mujeres e indígenas: cinco historias de discriminación en Guatemala". 2017, consultado febrero 4, 2020.

SURVIVAL. "Escolarización y pueblos indígenas". S. f., consultado marzo 8, 2020. https:// www.survival.es/sobre/escolarizacion

Tabio Mahates, Andrés y León Tellez Jianna. "El rol de la mujer indígena colombiana en el desarrollo de políticas públicas" (ponencia presentada en el Encuentro Nacional de Semilleros de Investigación de Facultades de Derecho, Bogotá D. C., septiembre 10-11, 2019).

UNESCO. "Política de colaboración de la UNESCO con los pueblos indígenas". S. f., consultado marzo 8, 2020. https://es.unesco.org/indigenous-peoples/policy

UNFPA, UNICEF, UN WOMEN. "Salud y mortalidad materna de las mujeres indígenas". S. f., consultado febrero 20, 2020. https://www.unfpa.org/sites/default/files/ resource-pdf/factsheet_v20_Spanish.pdf

United Nations. "Salud". S. f., consultado mayo 18, 2020. https://www.un.org/ development/ desa/indigenous-peoples-es/areas-de-trabajo/salud.html

Uribe, Erika. Un viaje ancestral. Mujeres afrocolombianas, indígenas y campesinas del Valle de Aburrá en diálogo de saberes intercultural". Revista Ratio Juris, vol. 13, n. ${ }^{\circ}$ 26 (julio 2018): 217-228. 